Twemlow, SW; Fonagy, P; (2005) The prevalence of teachers who bully students in schools with differing levels of behavioral problems. American Journal of Psychiatry, 162 (12) 2387 - 2389.

10.1176/appi.ajp.162.12.2387.

\title{
REPORT
}

\section{A Note on the Prevalence of Teachers Who Bully Students in Schools with Differing Levels of Behavioral Problems.}

Stuart W. Twemlow, M.D. *; Peter Fonagy, Ph.D., FBA**

*Professor of Psychiatry, Menninger Department of Psychiatry, Baylor College of Medicine, Houston Texas, Director Peaceful Schools and Communities Project and Medical Director HOPE unit, The Menninger Clinic, Houston Texas.

${ }^{* *}$ Freud Memorial Professor of Psychoanalysis, UCL, London, England; Director, The Anna Freud Centre, London, England

Corresponding author:

Stuart W Twemlow MD

The Menninger Clinic

PO Box 809045

2801 Gessner Drive

Houston, TX 77280-9045

stwemlow@aol.com

713-275-5436

Acknowledgements : Research supported by The Child \& Family Program of the Menninger Dept. Psychiatry, Baylor College Medicine, Houston, Texas. 
Twemlow, SW; Fonagy, P; (2005) The prevalence of teachers who bully students in schools with differing levels of behavioral problems. American Journal of Psychiatry, 162 (12) 2387 - 2389.

10.1176/appi.ajp.162.12.2387.

\section{ABSTRACT}

OBJECTIVE: To explore any relationship between the prevalence of teachers who bully students and school behavioral problems reflected in out-of-school suspensions. METHOD: A convenience sample of 214 teachers answered an anonymous questionnaire about their perceptions of teachers who bully students and their own practices. Teachers were grouped into whether they taught at low, medium or high suspension rate schools. ANOVAs were used to analyze continuous variables and chi-squared statistics for categorical variables. RESULTS: Teachers from high suspension rate schools reported they bullied more students, had experienced more bullying when they were students, had worked with more bullying teachers over the past three years and had seen more bullying teachers over the past year.

CONCLUSION: These findings suggest that teachers who bully students may have some role to play in the etiology of behavioral problems in school children. 
Twemlow, SW; Fonagy, P; (2005) The prevalence of teachers who bully students in schools with differing levels of behavioral problems. American Journal of Psychiatry, 162 (12) 2387 - 2389.

10.1176/appi.ajp.162.12.2387.

\section{Introduction}

In our research efforts to reduce bullying in elementary schools $(1,2)$, we felt it was important to explore whether manifest staff attitudes conducive to bullying may contribute to behavioral difficulties in children. We predicted that teachers who work in schools with high levels of behavioral problems will more commonly endorse attitudes accepting of bullying and perceive fewer differences between a hypothetical bullying teacher and a hypothetical non-bullying teacher in terms of behavior and motivation and that more teachers would admit to bullying students and more often report a history of bullying in the course of their own education.

\section{Method and Sample}

We defined a bullying teacher as one who uses his/her power to punish, manipulate or disparage a student beyond what would be a reasonable disciplinary procedure. Teachers from a representative sample of relatively demographically homogenous schools in a Midwestern school district were approached for participation in this study. Anonymous questionnaires were placed in each teacher's mailbox, and were delivered to an anonymous drop box. $75 \%$ of all teachers in eight elementary schools, four middle schools and three high schools participated (total school enrollment=4034, total number of teachers=214). Schools were grouped into low, ( 2 elementary, 1 middle, 1 high school), medium ( 2 elementary, 1 middle 1 high school ), or high ( 4 elementary, 1 middle,2 high schools ), levels of student behavioral problems according to out-of-school suspension rates, reported for the schools in the sample and teachers were grouped according to whether they taught at low, medium or high suspension rate schools. Demographic characteristics of the teachers showed no 
Twemlow, SW; Fonagy, P; (2005) The prevalence of teachers who bully students in schools with differing levels of behavioral problems. American Journal of Psychiatry, 162 (12) 2387 - 2389.

10.1176/appi.ajp.162.12.2387.

significant differences for age, gender or experience of the teachers, nor did schools

significantly differ in percent of minority students, percent special education students and

class size. Some schools with high suspension rates had a somewhat higher percentage of students on free lunch programs. We combined these variables into a simple risk indicator and used it as a covariate in univariate ANOVAS.

The questionnaire, available from the senior author, covered experience with bullying teachers, personal experience of bullying students, and characteristics of bullying and nonbullying teachers, rated on a 4 point likert scale ranging from never to always. Our previous work (3), has shown that bullying teachers can be classified into a sadistic type who spitefully humiliate students and hurt their feelings and a bully-victim type who fail to set limits and leave others to solve their problems ie bully reactively. Test-retest reliability was assessed over 3 weeks with 30 subjects, and was in excess of 0.8 across all scales. The two ratings of characteristics of bullying and non-bullying teachers were subtracted from each other to produce difference scores. The average squared discrepancy across subjects was considered to provide an indication of the extent to which teachers perceived differences between bullying and non-bullying colleagues. Nine items directly addressed attitudes to bullying in teachers, eg bullying teachers have quiet classrooms, uses needless force to discipline students, puts students down to get order in classroom, and these were aggregated to yield a single score indicating a favorable attitude towards bullying, ( Crombach's alpha $=0.65$ ). Analysis of variance was used to contrast teachers' rating on continuous variables and chi-squared statistics were applied to categorical variables. All means and percentages are reported in the table. 
Twemlow, SW; Fonagy, P; (2005) The prevalence of teachers who bully students in schools with differing levels of behavioral problems. American Journal of Psychiatry, 162 (12) 2387 - 2389.

10.1176/appi.ajp.162.12.2387.

\section{Results}

Our prediction that attitudes favoring bullying would be more characteristic of high or medium, rather than low suspension rate schools were not confirmed. That is, most teachers do not favor bullying attitudes. While teachers from high and low suspension rate schools rated bullying and non-bullying teachers similarly, there was a significant difference between teachers from low and medium suspension schools $(p<.03)$, with teachers from medium suspension schools seeing more differences than teachers from both high and low suspension schools.

Analysis of variance showed significant differences between low, medium and high suspension schools on four variables, confirming the remaining predictions. Teachers who reported that they bullied students were more often seen in high suspension schools $(p<.04)$. Teachers, who reported having experienced being bullied themselves as students, were more often working in high suspension schools $(p<.001)$. Teachers from high suspension schools also reported that they had seen other teachers bully students more often over the past year $(p<.001)$ and had worked with teachers over the past three years who had bullied students ( $\mathrm{p}<.0001)$.

\section{Discussion}

The study (by matching schools and using co-variate techniques) controlled for factors that are often associated with increasing behavioral problems in schools such as, high percentage of minority students, high percentage of special education students, class size and years of experience of teachers. None of these factors were found to significantly influence the 
Twemlow, SW; Fonagy, P; (2005) The prevalence of teachers who bully students in schools with differing levels of behavioral problems. American Journal of Psychiatry, 162 (12) 2387 - 2389.

10.1176/appi.ajp.162.12.2387.

findings. There was a trend for teachers from high and low suspension schools to see fewer differences between bullying and non-bullying teachers than teachers in medium suspension schools. These findings are consistent with the possibility that teachers in low suspension schools have less experience with bullying teachers and that teachers in high suspension schools where bullying teachers are more pervasive, sensitivity to bullying is eroded. Reporting of higher rates of teacher bullying behavior from high problem schools suggest that either teachers assimilate to the culture of violence that develops in such schools or that individuals with such predispositions drift towards or are more likely to remain in such institutions either because of preference or lack of opportunities to move to less dysfunctional locations. Since, transgenerational transmission of abuse is frequently reported in the literature, it is no surprise that teachers who experienced bullying as a child grow up to bully others and are more aware of teachers who bully students. Some teachers may drift towards or even contribute to the violent culture of problem schools rather than simply being made more violent by them.

There are obvious methodological limitations to this study. The sample is a convenience one, raising a problem of generalization, but the response rate of teachers was gratifyingly high. Although causal inferences cannot be made from these correlational findings, and the questionnaire lacks validation, it has good reliability. Nonetheless, the findings represent an initial contribution in a difficult area to study.

What can the clinician do about this problem? We know that overly negative, critical, bullying parental behavior contributes to and, if challenged therapeutically, can do much to reverse 
Twemlow, SW; Fonagy, P; (2005) The prevalence of teachers who bully students in schools with differing levels of behavioral problems. American Journal of Psychiatry, 162 (12) 2387 - 2389.

10.1176/appi.ajp.162.12.2387.

conduct problems in children (4), and we have been able to intervene successfully in schools using a model based on changing the responses of adults and children. The out-of-school suspension rate dropped significantly when these patterns were addressed $(5,6)$.

References:

1.Twemlow, SW, Sacco, FC, Williams, P: A Clinical and interactionist

Perspective on the bully/victim/bystander relationship. Bulletin of the Menninger

Clinic. 1996; 60(3): 296-313.

2. Twemlow SW, Fonagy P, Sacco F: The bystander role of teachers and students in the social architecture of bullying and violence in schools. In Press, 2004; Annals New York Academy of Sciences

3. Twemlow SW, Fonagy P, Sacco F, Brethour J, Teachers who bully students : a hidden trauma. Accepted for Publication, International Journal for Social Psychiatry, 2004.

4. Hartman, R. R., Stage, S. A., \& Webster-Stratton, C: A growth curve analysis of parent training outcomes: examining the influence of child risk factors (inattention, impulsivity, and hyperactivity problems), parental and family risk factors. Journal of Child Psychology and Psychiatry 2003; 44(3): 388-398.

5.Twemlow, SW, Fonagy, P, Sacco, FC, Gies, M, Evans, R, Ewbank, R: Creating a peaceful school learning environment: A controlled study of an elementary school intervention to reduce violence. American Journal of Psychiatry 2001; 158(5): 808-810. 
Twemlow, SW; Fonagy, P; (2005) The prevalence of teachers who bully students in schools with differing levels of behavioral problems. American Journal of Psychiatry, 162 (12) 2387 - 2389.

10.1176/appi.ajp.162.12.2387.

6. Twemlow, SW, Fonagy P, Sacco, FC: A social system - power dynamic approach for preventing school violence. Shafii, M, Shafii, S, (Eds.), School Violence:

Assessment, Management, and Prevention. Washington, DC: American Psychiatric Publishing, Inc., 2001. 


\begin{tabular}{|c|c|c|c|c|c|c|c|}
\hline & Total & $\begin{array}{l}\text { Low } \\
\text { Suspension } \\
\text { Schools } \mathrm{n}=4\end{array}$ & $\begin{array}{l}\text { Medium } \\
\text { Suspension } \\
\text { Schools } \mathrm{n}=4\end{array}$ & $\begin{array}{l}\text { High } \\
\text { Suspension } \\
\text { Schools } \mathrm{n}=7\end{array}$ & $\begin{array}{l}\text { Chi Square } \\
(\mathrm{df}=2)\end{array}$ & $\begin{array}{l}F_{2, x x x} \\
\text { ANCOVA }\end{array}$ & $p<$ \\
\hline $\begin{array}{l}\text { Mean Age Of } \\
\text { Teacher (SD) }\end{array}$ & $\begin{array}{l}42.0 \\
(10.1)\end{array}$ & $40.2(9.7)$ & $41.4(9.9)$ & $43.2(10.3)$ & & 2.4 & ns \\
\hline $\begin{array}{l}\text { Percent } \\
\text { Female }\end{array}$ & $79.0 \%$ & $79.0 \%$ & $85.0 \%$ & $74.0 \%$ & 5.5 & & ns \\
\hline $\begin{array}{l}\text { Mean Number } \\
\text { of Years of } \\
\text { Experience } \\
\text { (SD) }\end{array}$ & $\begin{array}{l}14.7 \\
(9.3)\end{array}$ & $13.8(9.5)$ & $15.1(8.9)$ & $14.8(9.4)$ & & $<1.0$ & ns \\
\hline $\begin{array}{l}\text { Mean Class } \\
\text { Size (SD) }\end{array}$ & $\begin{array}{l}20.1 \\
(8.7)\end{array}$ & $22.8(5.7)$ & $20.7(7.5)$ & $20.4(8.7)$ & & 2.3 & ns \\
\hline $\begin{array}{l}\text { Percent of } \\
\text { Students with } \\
\text { Subsidized } \\
\text { Lunch }\end{array}$ & $41.40 \%$ & $32 \%$ & $30 \%$ & $49 \%$ & 6.3 & & .05 \\
\hline $\begin{array}{l}\text { Percent Non- } \\
\text { white }\end{array}$ & $35.60 \%$ & $26.7 \%$ & $34.5 \%$ & $41.1 \%$ & 4.6 & & ns \\
\hline $\begin{array}{l}\text { Percent in } \\
\text { Special } \\
\text { Education }\end{array}$ & $25.70 \%$ & $18.7 \%$ & $23.6 \%$ & $30.8 \%$ & 4.2 & & ns \\
\hline $\begin{array}{l}\text { Discriminatio } \\
\text { n Between } \\
\text { Bullying and } \\
\text { Nonbullying } \\
\text { Teachers }\end{array}$ & $6.8(2.8)$ & $6.1(2.8)$ & $7.4(2.6)$ & 6.1 (3.0) & & $<1.0$ & ns \\
\hline $\begin{array}{l}\text { Attitudes } \\
\text { Favoring } \\
\text { Bullying }\end{array}$ & $2.4(.46)$ & $2.3(.45)$ & $2.4(.45)$ & $2.6(.48)$ & & 2.5 & .09 \\
\hline $\begin{array}{l}\text { Experienced } \\
\text { Of Having } \\
\text { Been Bullied }\end{array}$ & $\begin{array}{l}1.67 \\
.57)\end{array}$ & $1.47(.50)$ & $1.7(.63)$ & $1.76(.53)$ & & 7.0 & .001 \\
\hline $\begin{array}{l}\text { Teachers } \\
\text { Bullying } \\
\text { Students }\end{array}$ & $1.8(.96)$ & $1.5(.93)$ & $1.7(.93)$ & $2.0(.98)$ & & 3.3 & .04 \\
\hline
\end{tabular}


Twemlow, SW; Fonagy, P; (2005) The prevalence of teachers who bully students in schools with differing levels of behavioral problems. American Journal of Psychiatry , 162 (12) 2387 - 2389. 10.1176/appi.ajp.162.12.2387. 